\title{
Bioremediation of azo dyes using biogenic iron nanoparticles
}

\begin{abstract}
Rapid industrialization has led to release of toxic effluents in water which contaminate the ecosystem. With worldwide increase of textile industries in many countries significant use of synthetic complex organic dyes as colouring material have increased significantly. Azo dyes are widely used due to complex structures and high persistence to dye various materials such as leather, plastics, textiles, food, paper and cosmetics and their breakdown product have carcinogenic and mutagenic effects on various life forms. Biologically synthesized iron nanoparticles can degrade intermediate byproduct such as aromatic amines by various enzymes which are successfully utilized for the elimination of hazardous and toxic wastes due to their catalytic, supermagnetic property and greater efficiency. This mini review discusses the mechanism of biodegradation and decolorization of azo dyes by biogenic iron nanoparticles by optimizing various parameters. This suggested that iron nanoparticles are suitable for decolorization of textile effluents which is eco-efficient, less time consuming and economic approach.
\end{abstract}

Keywords: bioremediation, Azo dyes, iron nanoparticles, decolorization, ecofriendly
Volume 7 Issue I - 2019

\author{
Himani Sharma, Poonam Shirkot \\ Department of Biotechnology, DrYS Parmar University of \\ Horticulture \& Forestry, India
}

\begin{abstract}
Correspondence: Himani Sharma, Department of Biotechnology, DrYS Parmar University of Horticulture \& Forestry, Nauni, Solan (HP) 173230 India, Tel 94I8335484,
\end{abstract} Emailsharmahimani8@gmail.com

Received: September 27, 2017| Published: January 04, 2019

\section{Introduction}

From the beginning of human civilization natural matter was used to stain hides, decorate feathers and shells and paint stories on the walls of ancient caves to over 15,000 B.C. with black, white, yellow and reddish pigments made from ochre. After the Neolithic revolution the permanent settlement of man began resulting in new discoveries and inventions around 7,000-2,000 B.C. like production of textiles by adding various colorants to them. ${ }^{1}$ These natural organic colorants had timeless history of application, especially as textile dyes. The pioneer in discovery of synthetic dye was William Henry Perkin; a student at the Royal College of Chemistry who while making drug quinine from aniline produced thick dark sludge which he diluted with alcohol. This produced purple color 'fast' dye, resistant to washing and to the fading effects of light and was used to dye silk.

Thus, this discovery led to beginning of research and development in the field of dye manufacturing by others like Kekule's discovery of the molecular structure of benzene in 1865. In the beginning of the 20th century, synthetic dyestuffs had almost completely supplanted natural dyes. ${ }^{2}$ Synthetic dyes are extensively used in textile dyeing, paper printing, color photography, pharmaceutical, food, cosmetics and other industries. ${ }^{3}$ Annual worldwide production of synthetic dyes is estimated to be over $7 \times 10^{5}$ tons. In 1991, the world production of dyes was estimated $6,68,000$ tons of which azo dyes contributed $70 \%$ (ETAD, 1997). The world market for dyes, pigments and dye intermediates is estimated at about US \$23 billion consisting of dyes and pigment market of 1.3 million tones valued at US $\$ 16$ billion and dye intermediates market of US $\$ 7$ billion. After China, India is $2^{\text {nd }}$ largest producer, contributing to $80 \%$ of total dye industries of the world (Figure 1). ${ }^{4}$ The dyestuffs industry in India is concentrated in the states of Maharashtra and Gujarat, which hosts about 1200 plant and accounts for one-third of India's exports which mainly uses reactive dyes for the dyeing process because it gives a high degree of fixation.

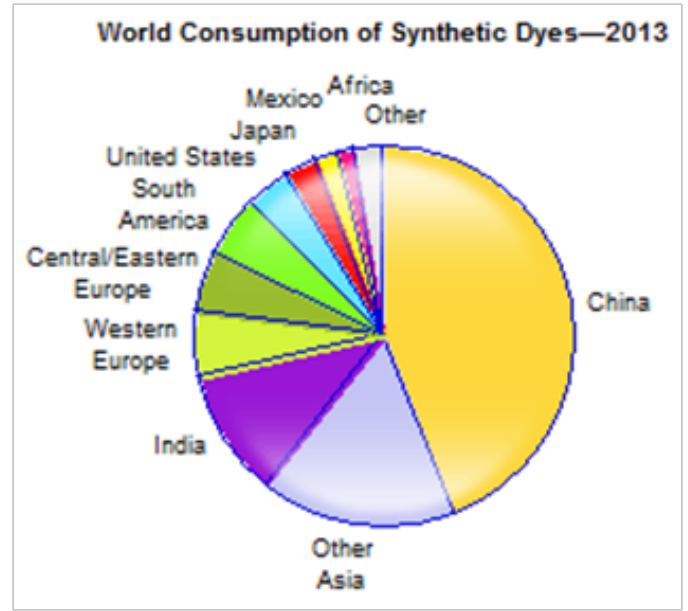

Figure I World consumption of synthetic dyes.

Two main components of azo dyes include chromophores $(-\mathrm{N}=\mathrm{N}-$ ), which produces color and links various aromatic amines, phenols etc. and auxochromes which supplement the chromophore by increasing its affinity towards fibers. ${ }^{5,6}$ The synthetic nature, strong and stable color, high organic content and complex aromatic structure of these dyes makes them more difficult to biodegrade. ${ }^{7}$ Further, fixation of these dyes on substrate is not very efficient and $10-15 \%$ of colored dye is released in waste water during dying process ${ }^{8}$ leading to reduction of water quality and contaminating the environment. ${ }^{9}$ Aquatic plants are most affected from these organic dyes as they reduce sunlight penetration into water and decrease the efficiency of photosynthesis and hence having adverse effect on their growth. Also, even a small quantity of dye molecules are toxic to aquatic life as they form thin layer over water bodies and cause severe damage including mutation and cancer to human beings, dysfunction of the kidneys, reproductive system, liver, brain and central nervous system. 


\section{Methods of preparation of azo dyes}

In order to minimize the toxicity of unnatural dyes to ecosystem various multi-technologies are available, including physical methods such as membrane filtration process (Nano- filtration, electro dialysis and reverse osmosis) and sorption techniques but it has major drawbacks such as limited life span of membrane, fouling of membrane and cyclic replacement of membrane. Electrochemical methods were described by, ${ }^{10-13}$ chemical methods ${ }^{14,15}$ includes coagulation and flocculation intergrated with filtration, ozonation, irradiation, adsorption, photolysis and ion pair extraction. These methods were used traditionally but are uneconomical for degradation of dyes from water bodies and have disposal problems of aggregated sediments, so are not commonly used. Further, they are not mostly used in waste water treatment as they are high energy demanding and requires large quantities expensive chemicals. In order to carry out environmental remediation of azo dye contaminations arising from its association with the efficient and inexpensive treatment, biological methods are favored.

Microbiological methods used with the help of pure enzymes such as hydroxylase and oxygenize takes much time to degrade dyes partially or fully and cannot degrade complicated dyes. ${ }^{16}$ Continuous efforts were made to degrading dye using isolated bacteria ${ }^{17,18}$ Pseudomonas luteola from waste water treatment plant that decolorize reactive azo dyes. ${ }^{19}$ isolated a bacterium Klebsiella pneumoniae from dye contaminated sludge that could degrade the methyl red upto $100 \mathrm{mg} / 1 \mathrm{more}$ efficiently than other isolated bacteria. The ability of two bacterial strains, the gram negative Alcaligenes faecalis and the gram positive Rhodococcus erythropolis to decolorize the monoazo dye acid orange were studied with different initial dye concentrations by. ${ }^{20}$ The diazo dye Reactive yellow 84A was efficiently degraded by a novel bacterial strain Exiguobacterium sp. Analytical techniques like HPLC, GCMS, and FTIR demonstrated that degradation of dye resulted with significant reduction of phyto toxicity, confirming the environmentally safe nature of the degradation metabolites. ${ }^{21}$

\section{Bioremediation of azo dyes by iron nanoparticles}

Bioremediation is the process of remediation of contaminated site by use of biological methods in which hazardous substances such as xenobiotics are broken down into less toxic or non toxic substances.
In order to carry out biodegradation process, strict conditions should be maintained as large scale operation is very difficult. Thus there is urgent need to use emerging technology such as nanotechnology for catalytic degradation of dyes. Recent research focused on the use of nanotechnology for environmental clean-up/remediation. Arising out of their ultrafine size, large surface area $\&$ interface dominated properties nano-sized materials can be used to decontaminate the toxic organic and inorganic chemical from the environments. Iron nanoparticles exhibit unique physical and chemical properties due to their limited size and a high density of corner or edge surface sites. ${ }^{22}$ Metal nanomaterials have attracted a great deal of attention because of their large applications in various fields like catalysis, sensors and environmental remediation like adsorption and degradation of various contaminants from aqueous media.

\section{Mechanism of degradation of azo dye}

Textile effluents containing dyes and other organic compounds require fast treatment or decolorization due to their toxic, health and environmental effects. Zero valent iron nanoparticles are intensively used as a reactive medium for wastewater treatment (containing chlorinated organic compounds, ${ }^{23}$ toxic metals ${ }^{24}$ and inorganic compound ${ }^{25,26}$ because the iron metal is of low cost, act as strong reducer, possess higher efficiency and contaminant degradation ability. Precipitation of these nanoparticles on bacterial surface increases their degradation potential for pollutants containing $-\mathrm{N}=\mathrm{N}-$ bond. On availability of electron donor such as NADH, NAD $(\mathrm{P}) \mathrm{H}$, these nanoparticles tend to catalyze the reduction of contaminants by donating $2 \mathrm{e}^{-}$to the dye $\mathrm{e}^{27,28}$ and thus act as strong reducer in the presence of enzyme azo reductase, so rendering them insoluble. ${ }^{29}$ In the destruction of toxic dyes, $\mathrm{Fe}^{0}$ nanoparticles gets oxidized and dye molecule undergoes reduction process. This particle exhibits an enhanced reactivity due to their larger surface $\operatorname{area}^{30}$ for the degradation of xenobiotic compounds (Figure 2). Recently many studies have been reported the increased reducing effect of $\mathrm{Fe}^{0}$ with different catalytic metal and supported nanoparticles. ${ }^{31}$ Over the years, laboratory studies have reported their growth in experiments and modification to have better surface properties, efficiency enhancement for reactions. ${ }^{32}$

$$
\begin{aligned}
& \mathrm{Fe}^{0}+2 \mathrm{H}^{+} \rightarrow \mathrm{Fe}^{2+}+\mathrm{H}_{2} \\
& -\mathrm{N} \mathrm{N}-+2 \mathrm{H}^{+}+2 \mathrm{e}^{-} \rightarrow-\mathrm{NH}-\mathrm{NH}- \\
& -\mathrm{NH}-\mathrm{NH}-+2 \mathrm{H}^{+}+2 \mathrm{e}^{-} \rightarrow-\mathrm{NH}_{2}+\mathrm{H}_{2} \mathrm{~N}-
\end{aligned}
$$

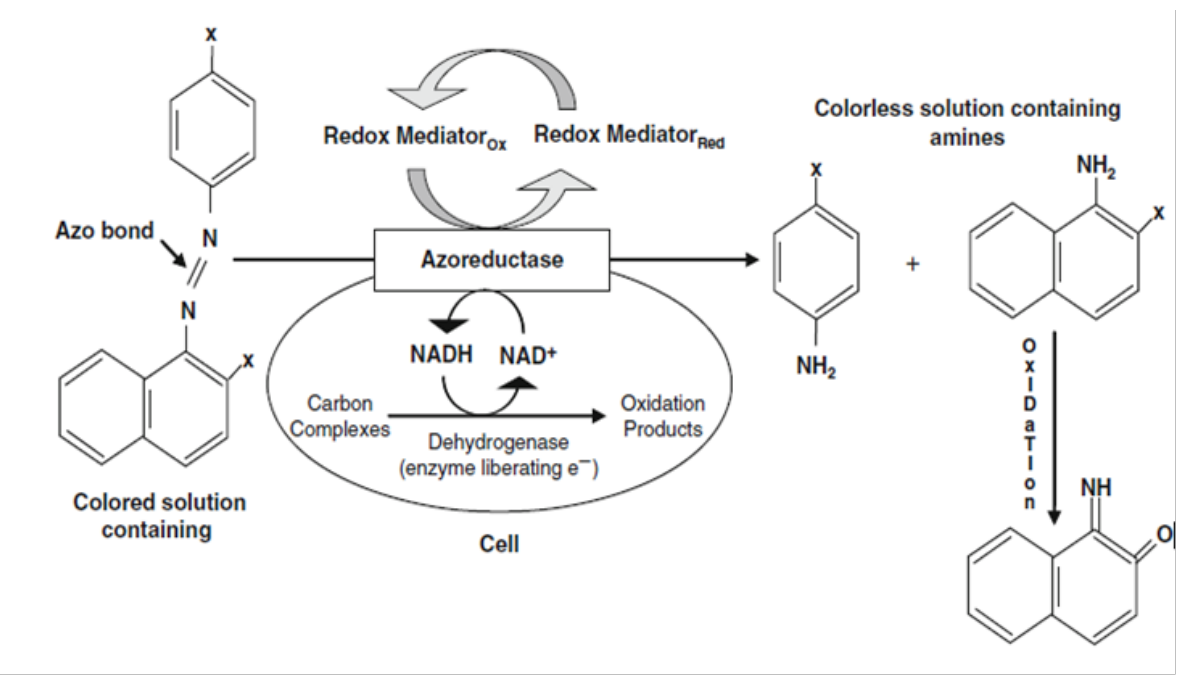

Figure 2 Possible mechanisms for the removal of azo dyes by bacteria. ${ }^{33}$ 


\section{Factors affecting biodegradation of dyes}

Biodegradation of azo dyes is dependent on various factors such as $\mathrm{pH}$, temperature, presence of oxygen, metals, salts etc. These abiotic factors are variable and changes with change in environment. Several researchers have discussed problems related to dye degradation which are least anticipated. Thus, bioiron nanoparticles, being a strong reducer, change these parameters as a result their potential to degrade these xenobiotics is also affected. Therefore, optimization of such conditions would greatly help in the development of large scale bioreactors for the efficient treatment of textile dyeing effluents and for the bioremediation of contaminated sites.

\section{$\mathrm{pH}$}

The $\mathrm{pH}$ of effluents from textile industry affects nanoparticles activity. The efficiency of dye decolorization is affected by change in $\mathrm{pH}$, the optimal $\mathrm{pH}$ for decolorization by iron nanoparticles is often between 8.0 and 10.0. In case of industrial processes which are performed under alkaline conditions, resistance to high $\mathrm{pH}$ is predominant. The $\mathrm{pH}$ has a major effect on the efficiency of dye decolorization; the optimal $\mathrm{pH}$ for color removal in bacteria is often between 6.0 and 10.0. ${ }^{34}$

\section{Temperature}

Temperature plays an important role in bioremediation of wastewater. With increase in temperature, rate of degradation also increases upto certain level and after that saturation is achieved and decline in decolorization activity takes place. Decolorization of Disperse Blue 79 and Acid Red 315 in P. sajor-caju was observed in temperature range between $30^{\circ} \mathrm{C}$ to $40^{\circ} \mathrm{C} .{ }^{35}$ The decolorization rate of Reactive Black 5 by Enterococcus sp. EC3 was found to increase with rise in temperature from $22^{\circ} \mathrm{C}$ to $37^{\circ} \mathrm{C}$, and was found to be affected drastically at $42^{\circ} \mathrm{C}$. Optimum temperature for decolorization was at $37^{\circ} \mathrm{C} .{ }^{36}$

\section{Dye concentration}

Azo dyes being toxic in nature affects the decolorization process. ${ }^{37,38}$ With increase in concentration of dye, rate of decolorization decreases as active sites of azo reductase are blocked by dye molecules with different structures ${ }^{38}$ observed an inverse relationship between the velocity of the decolorization reaction and the dye concentrations between 100 and $500 \mathrm{mg} \mathrm{L} 1$ azo dye (Reactive Black 5, Direct Red 81, Acid Red 88, and Disperse Orange 3) by Shewanella putrefaciens

\section{Salt concentration}

$15-20 \%$ of salt concentration found in effluents discharged from wastewater is toxic to the ecosystem and may pollute the environment. Further bio-iron nanoparticles are not able to work efficiently at high $\mathrm{NaCl}$ concentrations as most microorganisms are not active in these conditions and are not able to degrade dyes. Two bacterial Shewanella species, $S$. putrefaciens and $S$. oneidensis, previously selected on the basis of their ability to degrade azo dyes, were also tested in saline medium at different salt concentrations of up to $10 \%$ to evaluate their potential to decolorize four structurally different azo dyes: Reactive Black 5, Direct Red 81, Acid Red 88, and Disperse Orange 3. Full decolorization was reached at salt concentrations up to $6 \% .{ }^{38}$ Other factors which are also involved in degradation of dyes include nutrient source such as carbon and nitrogen, oxygen and agitation, dye structure, electron donor and redox mediator. ${ }^{39}$
In conclusion, there is much recent interest in the use of iron nanoparticles for biodegradation of toxic azo dyes which contaminate the environment. Optimization of various parameters like temperature, $\mathrm{pH}$, salinity and use of growth supplements such as yeast extract can further enhance the biodegradation activity. Bio-iron nanoparticles deliver promising approach for treatment of effluents as they are feasible and cost effective. In order to effectively use the bioremediation tool for degradation and detoxification of dyes a thorough understanding of microbial genetics, biochemistry and physiology is essential. More concerted efforts are required to establish the microbial decolorization process. In general, the attention in this field is not enough and additional studies should be conducted to increase the knowledge in this field. In addition, health impacts and environmental fate of these nanomaterials need to be addressed before their widespread application.

\section{Acknowledgments}

None.

\section{Conflicts of interest}

Authors declare that there is no conflict of interest.

\section{References}

1. Grierson JR, Link JM, Mathis CA, et al. A radiosynthesis of [F-18] fluoromisonidazole. J Nucl Med. 1989;30(3):343-350.

2. Welham A. The theory of dying (and the secret of life). Journal of the Society of Dyers and Colourists. 2000;116(5):140-143.

3. Rafii F, Franklin W, Cerniglia. Azoreductase activity of anaerobic bacteria isolated from human intestinal microflora. Appl Environ Microbiol. 1990;56(7):2146-2151.

4. Ghaly AE, Ananthashankar R, Alhattab M, et al. Production, characterization and treatment of textile effluents: A Critical Review. Journal of Chemical Engineering and Process technology. 2014;5(1):182-200.

5. Stolz A. Basic and applied aspects in the microbial degradation of azo dyes. Applied Microbiology and Biotechnology. 2001;56(1-2):69-80.

6. Leub H. Industrial dyes, chemistry, properties and applications. Wenheim, Germany: Wiley VCH; 2003.

7. Gupta VK, Suhas. Application of low cost adsorbents for dye removal-a review. J Environ Manage. 2009;90(8):2313-2342.

8. Pourbabaee AA, Malekzadeh F, Sarbolouki MN, et al. Aerobic decolorization and detoxification of a disperse dye in textile effluent by a new isolate of Bacillus sp. Biotechnol Bioeng. 2006;93(4):631-635.

9. Bayramoglu G, Elik C, Arica MY. Biosorption of reactive blue 4 dye by native and treated fungus batch and continuous flow system studies. $J$ Hazard Mater. 2006;137(3):1689-1697.

10. Nobutake S, Nagai T, Hotta H, et al. The Radiation-Induced Degradation of Azo Dyes in Aqueous Solutions. The International Journal of Applied Radiation and Isotopes. 1975;26(12):726-730.

11. Hosono M, Arai H, Aizawa M, et al. Decoloration and Degradation of Azo Dye in Aqueous Solution Supersaturated with Oxygen by Irradiation of High-Energy Electron Beams. Applied Radiation and Isotopes. 1993;44(9):1199-1203.

12. Bagyo, Agustin NM, Hidehiko A, et al. Radiation-induced decoloration and sedimentation of colloidal disperse dyes in water. Applied Radiation and Isotopes. 1997;48(2):175-181. 
13. Daneshvar N, Ashassi-Sorkhabi H, Tizpar A. Decolorization of orange II by electrocoagulation method. Separation and Purification Technology. 2003;31(2):153-162.

14. Zhang F, Yediler A, Liang X, et al. Effects of dye additiycs on the ozonation process and 41 Oxidation by-Products: A Comparative Study Using Hydrolyzed c.1. Reactive Red 120. Dyes and Pigments. 2004;60(1):1-7.

15. Zhang F, Yediler A, Liang X, et al. Ozonation of the purified hydrolyzed azo dye reactive red 120 (Ci). Journal of Environmental Science and Health Part A-Toxic/Hazardous Substances \& Environmental Engineering. 2002;37(4):707-713.

16. Can OT, Kobya M, Demirbas E, et al. Treatment of the textile wastewate by combined electrocoagulation. Chemosphere. 2006;62(2):181-187.

17. Zimmermann LK, Hantke K, Braun V. Exogenous induction of the iron dicitrate transport system of Escherichia coli K-12. J Bacteriol. 1984;159(1):271-277.

18. $\mathrm{Hu}$ TL. Degradation of azo dyes RP2B by Pseudomonas Luteola. Water Science Technology. 1998;38(4-5):299-306.

19. Wong PK, Yuen PY. Decolorization and biodegradation of methyl red by Klebsiella pneumoniae RS-13. Water Research. 1996;30(7):1736-1744.

20. Mutafov S, Avramova T, Stefanova L, et al. Decolorization of acid orange by bacteria of different tinctorial type: a comparative study. World Journal of Microbiology and Biotechnology. 2007;23(3):417-422.

21. Dhanve RS, Kalyani DC, Phugare SS, et al. Coordinate action of exiguobacterial oxidoreductive enzymes in biodegradation of reactive yellow 84A dye. Biodegradation. 2009;20(2):245-255.

22. Fernandez-Garcia M, Martinez-Arias A, Hanson JC, et al. Nanostructured Oxides in Chemistry: Characterization and Properties. Chemical Review. 2004;104(9):4063-4104.

23. Song H, Carraway ER. Reduction of chlorinated ethanes by nanosized zero-valent iron kinetics, pathways and effects of reaction conditions. Environmental Science and Technology. 2005;39(16):6237-6245.

24. Lin KS, Chang NB, Chuang TD. Fine structure characterization of zero valent iron nanoparticles for decontamination of nitrites and nitrates in waste and ground water. Science and Technology of Advanced Material. 2008;9(2):1-9.

25. Lien HL, Wilkin RT. High-level arsenite removal from ground water by zero valent iron. Chemosphere. 2005;59(3):377-386.

26. Wang H, Zheng XW, Su JQ, et al. Three dimensional nanostructured substrates toward efficient capture of circulating tumor cells. Angew Chem Int Ed Engl. 2009;48(47):8970-8973.
27. Chatterjee S. Removal of reactive black 5 by Zero valent iron modified with various surfactants. Chemical Engineering Journal. 2010;160(1):27-32.

28. Crini G. Non-conventional low-cost adsorbents for dye removal: a review. Bioresource Technology. 2006;97(9):1061-1085.

29. Otto M, Floyd M, Bajpai S. Nanotechnology for site remediation. Journal of Remediation. 2008;19(1):99-108.

30. Sun YP, Li X, Cao J, et al. Characterization of zero-valent iron nanoparticles. Advances in Colloid and Interface Science. 2006;120(13):47-56.

31. Trujillo-Reyes J, Sanchez-Mendieta V, Colin-Cruz A, et al. Removal of Indigo Blue in aqueous solution using $\mathrm{Fe} / \mathrm{Cu}$ Nanoparticles and $\mathrm{C}$ $\mathrm{Fe}-\mathrm{Cu}$ nanoalloy composites. Water, Air, and Soil Pollution. 2010;207(14):307-317.

32. Khalil H, Mahajan D, Rafailovich M, et al. Synthesis of zero valent nanophase metal particles stabilized with poly (ethylene glycol) Langmuir. 2004;20(16):6896-6903.

33. Pearce CI, Christie R, Boothman C, et al. Reactive azo dye reduction by Shewanella strain J18143. Biotechnology Bioengineering. 2006;95(4):692-703

34. Chen $\mathrm{K}, \mathrm{Wu}$ J, Liou D, et al. Decolorization of the textile dyes by newly isolated bacterial strains. Journal of Biotechnology. 2003;101(1):57-68.

35. Joe MH, Lim SY, Kim DH, et al. Decolorization of reactive dyes by Clostridium bifermentans SL 186 isolated from contaminated soil. World Journal of Microbiology Biotechnology. 2008;24(10):2221-2226.

36. Wang Z, Peng P, Huang W. Dechlorination of n-hexachlorocyclohexane by zero-valent metallic iron. Journal of Hazardous Materials. 2009;166:992-997.

37. Ahwany El. Decolorization of fast red by metabolizing cells of Oenococcus oeni ML34. World Journal of Microbiology and Biotechnology. 2008;24(8):1521-1527.

38. Khalid A, Arshad M, Crowley DE. Decolorization of azo dyes by Shewanella sp. Under saline conditions. Applied Microbiology and Biotechnology. 2008;79(6):1053-1059.

39. Khan AA, Husain Q. Potential of plant polyphenol oxidases in the decolorization and removal of textile and non-textile dyes. Journal of Environment Science. 2007;19(4):396-402. 